\title{
A Synergistic Effect of Chitosan and Lactic Acid Bacteria on the Control of Cruciferous Vegetable Diseases
}

\author{
Yu-Chen Lin ${ }^{1}$, Kuang-Ren Chung (i) ${ }^{1 *}$, and Jenn-Wen Huang (iD) 1,2* \\ ${ }^{1}$ Department of Plant Pathology, National Chung Hsing University (NCHU), Taichung 40227, Taiwan \\ ${ }^{2}$ Innovation and Development Center of Sustainable Agriculture (IDCSA), NCHU, Taichung 40227, Taiwan
}

(Received on January 1, 2020; Revised on February 21, 2020; Accepted on March 9, 2020)

Two lactic acid bacteria (LAB) designated $\mathrm{J02}$ and $\mathrm{J} 13$ were recovered from fermented vegetables based on their ability to suppress soft rot disease caused by Pectobacterium carotovorum subsp. carotovorum (Pcc) on radish. J02 and J13 were identified as Lactobacillus pentosus and Leuconostoc fallax, respectively. The ability of $\mathrm{J02}$ and $\mathrm{J13}$ to suppress plant diseases is highly dependent on chitosan. LAB alone has no effect and chitosan alone has only a moderate effect on disease reduction. However, J02 or J13 broth cultures plus chitosan display a strong inhibitory effect against plant pathogens and significantly reduces disease severity. LAB strains after being cultured in fish surimi (agricultural waste) and glycerol or sucrose-containing medium and mixed with chitosan, reduce three cruciferous vegetable diseases, including cabbage black spot caused by Alternaria brassicicola, black rot caused by Xanthomonas campestris pv. campestris, and soft rot caused by Pcc. Experimental trials reveal that multiple applications

\footnotetext{
*Corresponding authors.

K.-R. Chung

Phone) +886-4-2284-0780 ext. 301, FAX) +886-4-2287-7585

E-mail) krchung@nchu.edu.tw

J.-W. Huang

Phone) +886-4-2284-0780 ext. 351, FAX) +886-4-2287-7585

E-mail) jwhuang@dragon.nchu.edu.tw

ORCID

K.-R. Chung

https://orcid.org/0000-0002-2640-2951

J.-W. Huang

https://orcid.org/0000-0003-0798-4332

(c) This is an Open Access article distributed under the terms of the Creative Commons Attribution Non-Commercial License (http:// creativecommons.org/licenses/by-nc/4.0) which permits unrestricted noncommercial use, distribution, and reproduction in any medium, provided the original work is properly cited.
}

Articles can be freely viewed online at www.ppjonline.org. are more effective than a single application. In-vitro assays also reveal the $\mathrm{J02}$ /chitosan mixture is antagonistic against Colletotrichum higginsianum, Sclerotium rolfsii, and Fusarium oxysporum f. sp. rapae, indicating a broad-spectrum activity of LAB/chitosan. Overall, our results indicate that a synergistic combination of $L A B$ and chitosan offers a promising approach to biocontrol.

Keywords : agricultural wastes, glycerol, surimi

Handling Editor : Mee Kyung Sang

Cruciferous vegetables belonging to the family of Brassicaceae contain a number of genera, species, and cultivars, which are commonly cultivated for food production. A number of fungal and bacterial pathogens can attack cruciferous vegetables and cause severe yield losses. Pesticides are routinely used to prevent or mitigate damage caused by plant pathogenic fungi and bacteria in conventional agriculture. The use of pesticides has more restrictions on organic farms than conventional farms. To reduce toxic chemicals used in organic farming, the focus has recently been directed towards the development of biological control measures using beneficial microorganisms. Beneficial microorganisms are present ubiquitously in diverse environments including phyllosphere, rhizosphere, food products, and agricultural wastes. Biological control using beneficial microorganisms has been reported with limited success on cruciferous vegetables (Hassan et al., 2017; Huang et al., 2018). In addition, there has been an increasing interest in the recycling of agricultural wastes to culture beneficial microorganisms for plant disease management in organic farming (Litterick et al., 2004).

Chitosan is one of the best examples of recyclable materials from agricultural wastes. Chitosan is often generated by dissolving chitin shells of shrimps or other crustaceans 
with sodium hydroxide. Chitosan is a linear, positive charge polysaccharide composed of glucosamine subunits and has been widely used in pharmaceuticals, medicine, cosmetics, biotechnology, agriculture, and food industry (Morin-Crini et al., 2019). In agricultural production, chitosan is used to reduce diseases because it is toxic to a wide range of pathogens including fungi (Hassan and Chang, 2017), bacteria (El Hadrami et al., 2010), and viruses (Chirkov, 2002). Chitosan has been shown to increase membrane permeability, induce the accumulation of cellular reactive oxygen species, damage nucleic acids, and eventually lead to cell death in fungi and bacteria (Lopez-Moya et al., 2019; Verlee et al., 2017). Chitosan can also deplete metal ions and trace elements required for microbial growth (Rabea et al., 2003). After being applied to plants as a soil amendment, by spraying, or via seed treatment, chitosan is capable of activating the immune system and triggering the de-novo synthesis of pathogenesis-related proteins, antimicrobial compounds (e.g., phytoalexin, polyphenol, and lignin), and enzymes (Hadwiger, 2013; Hassan and Chang, 2017; Lin et al., 2005; Xing et al., 2015). Chitosan has been shown to promote plant growth and reduce pre- and postharvest diseases (Abd-El-Kareem et al., 2006; Hassan and Chang, 2017). Because chitosan is water-insoluble and readily dissolved in acids, a combination of chitosan and an acidproducing bacterium may improve the efficacy of chitosan in the suppression of plant diseases.

Lactic acid bacteria (LAB) are commonly present in decomposing plants, fermenting foods, and milk products (Mokoena, 2017). LAB strains convert carbohydrates to form lactic acid, which can acidify the surroundings and inhibit the growth of spoilage agents (Crowley et al., 2013), and thus are commonly used in fermenting foods. LAB strains are also an important group of probiotic microorganisms, which can facilitate lactose digestion and enhance the immune system (Colombo et al., 2018). In addition to the production of organic acids, some strains of LAB can produce antimicrobial secondary metabolites (Axel et al., 2016; Laitila et al., 2002). In plant pathology, many LAB strains have been evaluated for their ability to reduce a wide range of diseases (Daranas et al., 2019; Shrestha et al., 2014). LAB strains have also been reported to trigger plant defense system, which might contribute to the reduction of the bacterial wilt disease caused by Ralstonia solanacearum in tomato (Konappa et al., 2016).

In the present study, we explore the possibility of LAB for controlling fungal and bacterial diseases of cruciferous vegetables. Two LAB strains were isolated from fermented vegetables. The ability of the newly identified LAB strains to suppress plant pathogens and to reduce disease severity on cabbage was highly dependent on chitosan. Chitosan alone displayed a limited effect on disease suppression. Chitosan was readily dissolved in LAB broth cultures. Experiments were also performed to identify cheaper and effective ingredients that could be used to culture LAB. As a result, fish surimi, commonly used as foods and agricultural feeds, was found to be a superior nitrogen source to culture $\mathrm{LAB}$, which will likely reduce the production costs in future. Overall, our results have shown that chitosan and LAB function in a synergistical manner to suppress various diseases of cruciferous vegetables. The current study is an example of how to develop eco-friendly biopesticide products for disease management by combing beneficial microorganisms and agricultural wastes.

\section{Materials and Methods}

Microorganisms and culture conditions. Plant pathogenic fungi and bacteria used in this study and their origins are listed in Table 1. Fungal pathogens were cultured on

Table 1. Origins of plant pathogenic fungi and bacteria used in this study

\begin{tabular}{|c|c|c|c|}
\hline Pathogen & Strain & Original host & Location \\
\hline Alternaria brassicicola (Schwein.) Wiltshire & ABA31 & $\begin{array}{l}\text { Chinese cabbage (Brassica rapa subsp. } \\
\text { pekinensis Lour. Hanelt) }\end{array}$ & Dali, Taichung \\
\hline Colletotrichum higginsianum Sacc. & PA01 & Pak Choi (B. rapa subsp. chinensis) & Xiluo, Yunlin \\
\hline $\begin{array}{l}\text { Fusarium oxysporum f. sp. rapae (Enya, Togawa, } \\
\text { Takeuchi \& Arie) }\end{array}$ & Focn38 & Mustard (B. juncea (L.) Czern.) & Xiluo, Yunlin \\
\hline Sclerotium rolfsii Sacc. & SR & Taro (Colocasia esculenta (L.) Schott). & Dajia, Taichung \\
\hline $\begin{array}{l}\text { Pectobacterium carotovorum subsp. carotovorum } \\
\text { (Jones) Hauben, Moore, Vauterin, Steenackers, } \\
\text { Mergaert, Verdonck \& Swings }\end{array}$ & ZL3 & $\begin{array}{l}\text { Colored Calla Lily (Zantedeschia } \\
\text { aethiopica (L.) Spreng) }\end{array}$ & Wuri, Taichung \\
\hline $\begin{array}{l}\text { Xanthomonas campestris pv. campestris } \\
\text { (Pammel) Dowson }\end{array}$ & XCC70 & Cabbage (Brassica oleracea var. capitate (L.)) & Changhua, Taiwan \\
\hline
\end{tabular}


potato dextrose agar (PDA, pH 5.6; Difco, Sparks, MD, USA), and incubated in an incubator with $12 \mathrm{~h}$ daily illumination at $25^{\circ} \mathrm{C}$. Bacterial pathogens were cultured on nutrient agar (NA, pH 6.8; Difco) plate at $30^{\circ} \mathrm{C}$. De Man, Rogosa and Sharpe (MRS) medium, each liter containing $10 \mathrm{~g}$ Proteose peptone No. 3, $10 \mathrm{~g}$ beef extract, $20 \mathrm{~g}$ dextrose, 1 $\mathrm{g}$ Tween $80,5 \mathrm{~g}$ yeast extract, $2 \mathrm{~g}$ ammonium citrate, $5 \mathrm{~g}$ sodium acetate, $0.1 \mathrm{~g}$ magnesium sulfate, $2 \mathrm{~g}$ dipotassium phosphate, and $0.05 \mathrm{~g}$ manganese sulfate, $\mathrm{pH}$ 6.2 (De Man et al., 1960) was used to culture LAB from fermented vegetables. A MRSSG medium ( $\mathrm{pH}$ 4.1) was modified from MRS by replacing peptone, beef extract, and dextrose with $1.5 \%$ (v/v) surimi (fish soluble liquid, Regrowth Trading, Kaohsiung, Taiwan) and 1.5\% (v/v) glycerol. A MRSSS medium (pH 5.3) contained $1.5 \%$ surimi and $0.5 \%$ sucrose as the main nitrogen and carbon source, repectively. Both MRSSG and MRSSS were also used to culture LAB. Unless otherwise stated, $\mathrm{LAB}$ were cultured at $37^{\circ} \mathrm{C}$.

Isolation of $\mathrm{LAB}$ from fermented vegetables. Fermented Chinese cabbage (Brassica rapa pekinensis) (catalog number PA050) was purchased from Chengfu Shengji Food (Hsinchu, Taiwan). Fermented spicy mustard (Brassica juncea (L.) Czern) was purchased from Liancheng Agricultural Products Processing Factory (Taichung, Taiwan). Juice of fermented vegetables was serially diluted and plated out onto MRS agar plates, which were incubated in a $37^{\circ} \mathrm{C}$ incubator for $36 \mathrm{~h}$. Bacterial colonies were picked and subsequently streaked 3 times for single colonies. Antagonistic activity was assayed on a filter paper disc $(8 \mathrm{~mm}$ in dia.) overlaid on the lawn of Pectobacterium carotovorum subsp. carotovorum (Pcc) ZL3 (Table 1). The PccZL3 strain was pre-cultured on NA for 2 days and a filter paper disc was placed in the center of the plate. LAB strains were cultured in MRS for 5 days and broth cultures $(50 \mu \mathrm{l})$ were placed on a filter paper disc. The plate was incubated at $30^{\circ} \mathrm{C}$ for 2 days for the formation of an inhibition zone.

Antagonistic activity was further assayed on radish. White radish (Raphanus sativus L. var. Longipinnatus) purchased from local markets were surface-sterilized with $1 \%$ sodium hypochlorite for $5 \mathrm{~min}$, rinsed 3 times with sterile water, air-dried, and cut into slices of $0.5-\mathrm{cm}$ thick. A sterile filter paper disc was placed in the center of the radish slices. Broth cultures of LAB after being grown in MRS for 3 days and mixed with or without chitosan (Charming \& Beauty, Taoyuan, Taiwan) were mixed with an equal volume of 3 to 5-day PccZL3 culture suspensions $\left(10^{8}\right.$ colony-forming unit $\left.[\mathrm{cfu}] / \mathrm{ml}\right)$, from which $70 \mu \mathrm{l}$ was placed on a filter paper disc after being diluted with sterile distilled water to $200 \times$ and $400 \times$. Radishes treated with wa- ter, MRS, $2 \%$ lactic acid (LA, $\mathrm{pH} 4.1$ ), or MRS containing $2 \%$ LA were used as mock controls. All radish slices were placed in a plastic box and incubated at $30^{\circ} \mathrm{C}$ for 2 days. Each treatment contained four replicates.

Identification of LAB. Bacterial strains were streaked on the biolog universal growth plates (Biolog, Hayward, CA, USA), incubated at $37^{\circ} \mathrm{C}$ for $24 \mathrm{~h}$ for single colonies, tested for physiological metabolisms using a Biolog GEN III microplate, and identified using Biolog MicroLog/Microstation according to the manufacture's recommendations. Further identification of bacteria was performed by sequence analysis of a 16 rRNA gene, which was amplified by PCR with the primers fD1 (5'-ccgaattcgtcgtcgacaacagagtttgatcctggctcag- $\left.3^{\prime}\right)$ and rp1 (5'-cccgggatccaagcttacggttaccttgttacgactt-3') (Weisburg et al., 1991). DNA fragments were directly sequenced using an Applied Biosystem 3730 DNA analyzer at Tri-Biotech (Taipei, Taiwan). Similarity searching was performed at the National Center for Biotechnology Information (NCBI) using the BLASTX program. Sequence data from this article has been deposited in the EMBL/GenBank data libraries under accession numbers: MN396542 (J02) and MN396543 (J13).

Optimizing the antagonistic effect of LAB grown in different carbon and nitrogen sources. $L A B$ strains were cultured in a modified MRS by altering the main carbon or nitrogen source to determine the most effective combination for antagonistic activity. To identify an effective nitrogen source, both proteose peptone and beef extract in MRS were omitted and replaced with $2 \%(\mathrm{w} / \mathrm{v})$ each of soya peptone, casein, skim milk, tryptone, glutamic acid, and tyrosine. Two agricultural wastes, surimi and chicken feather meal, were also tested. To identify an effective carbon source, dextrose was replaced with $2 \%(\mathrm{w} / \mathrm{v})$ each of fructose, sucrose, dextrin, maltose, glycerol, and corn meal. Broth cultures of LAB strains were grown in MRS or modified MRS for 3 to 5 days and $1 \%(\mathrm{w} / \mathrm{v}$ ) chitosan was added. Broth cultures were diluted with sterile water to $400 \times$, mixed with an equal volume of bacterial suspensions collected from PccZL3 $\left(10^{8} \mathrm{cfu} / \mathrm{ml}\right)$, and applied onto radish as described above.

Assays for antagonistic activities against various plant pathogens. Assays for spore germination were performed by placing spore suspensions $\left(3 \times 10^{4}\right.$ spores $\left./ \mathrm{ml}\right)$ prepared from fungal pathogens: Alternaria brassicicola ABA31, Colletotrichum higginsianum PA01, or Fusarium oxysporum f. sp. rapae Focn38 (Table 1) and mixed with an equal volume of LAB broth cultures on a glass slide, which 
was placed on the top of a L-shaped rod and incubated in a glass Petri dish for 8-12 $\mathrm{h}$ in the complete darkness. Spores mixed with water were used as a mock control. Unless otherwise indicated, 100 randomly selected spores were examined microscopically. Sclerotia $(n=50)$ produced by Sclerotium rolfsii SR grown on PDA at $28^{\circ} \mathrm{C}$ for 7 days were soaked in water or LAB broth cultures for $12 \mathrm{~h}$ and transferred to $1.5 \%$ water agar medium for germination. The antagonistic activity against Xanthomonas campestris pv. campestris $(X c c) 70$ was assessed by placing $20 \mu \mathrm{l}$ of LAB broth cultures on an 8-mm filter paper placed in the center of bacterial lawn and incubating at $30^{\circ} \mathrm{C}$ for 2-3 days. Bacterial lawn was prepared by mixing $X c c 70$ suspensions with NA $\left(45^{\circ} \mathrm{C}\right)$, which was then poured on Petri dish. Each treatment contained at least three replicates and all experiments were repeated twice. Percentage (\%) of inhibition was calculated by dividing the relative difference of inhibition rates between mock control and treatment over that of the control and multiplied by 100 .

Inoculation and disease control assays. The effect of LAB against $P c c$ ZL3 was assessed on detached cabbage leaf petioles. Ten microliters of PccZL3 suspensions $\left(10^{8}\right.$ $\mathrm{cfu} / \mathrm{ml}$ ) after being mixed with broth cultures of LAB to $2 \times, 100 \times, 200 \times$, and $400 \times$ were applied to longitudinal section of leaf petioles. The treated leaves were kept in a plastic box for 2 days for lesion development. Petioles treated with water and PccZL3 only were used as controls.

Biocontrol against $A$. brassicicola ABA31 was performed on cabbage seedlings and detached leaves. Cabbage (Brassica oleracea L. Capitata group) cv. Gaofeng seeds were purchased from Known-You Seed (Kaohsiung, Taiwan). Seeds were sterilized in 1\% sodium hypochlorite for $5 \mathrm{~min}$, rinsed 3 times with sterile water, and incubated on Petri dishes for 3 days. Seedlings were planted in peat moss (BVB no. 4, Bas Van Buuren, Coldenhovelaan, The Netherland) in an $8 \times 16$ plastic tray for 10 days, transplanted to 3 -inch pots filled with peat moss, and maintained in a greenhouse. Plants were applied with $1000 \times$ Hyponex No. 2 fertilizer (Hyponex, Marysville, OH, USA) once a week for 3 to 4 weeks. The effect of LAB grown in a modified MRS and mixing with chitosan on the control of cabbage black spot disease was evaluated on detached cabbage leaves. The third and fourth leaves of 28-dayold cabage plants were surface-sterilized with $1 \%$ sodium hypochlorite, rinsed 3 times with sterile water, air-dried, and used for inoculation. Leaves were inoculated by placing $5 \mu 1$ each of LAB broth cultures and ABA31 suspensions $\left(3 \times 10^{4}\right.$ spores $\left./ \mathrm{ml}\right)$ on detached cabbage leaves. The leaves were kept in a damp Petri dish for 5 days for lesion development. Biocontrol against ABA31 was also assessed in greenhouse conditions. Broth cultures of LAB were applied to the leaves of 28-day-old cabbage plants by homogeneously spraying to run-off with an air compressor (SIL-AIR 30 HA, Werther International, via Brunelleschi, Reggio Emilia RE, Italy) with air pressure set at $1 \mathrm{~atm}$. The compressor was at 10 to $15 \mathrm{~cm}$ away from leaves. Broth cultures of LAB were serially diluted $200 \times$ and applied uniformly to cabbage seedlings 1 day before or after the inoculation or co-applied with conidial suspensions $(3 \times$ $10^{4}$ spores $/ \mathrm{ml}$ ) prepared from ABA31. The effect of LAB application frequency was evaluated by spraying broth cultures of LAB over cabbage seedlings at days 14, 21, and 28 (three applications), days 21 and 28 (two applications), or day 28 (one application) after transplant. Cabbage seedlings were inoculated by spraying spore suspensions of $\mathrm{ABA} 31$ at day 29.

Biocontrol against $X c c 70$ was performed by uniformly spraying broth cultures of LAB over cabbage seedlings with an air compressor and challenged with $X c c 70$ suspensions $\left(10^{8} \mathrm{cfu} / \mathrm{ml}\right)$ by a spraying or scissor-cutting method. All test plants were covered with plastic bags for $24 \mathrm{~h}$ and maintained in a greenhouse after plastic bags were removed. Disease severity on the 3rd and 4th leaves was recorded 7 days post inoculation. Disease severity was determined using the following scale: 0 , no lesions; 1 , lesion areas between 1 and 5\%; 2, lesion areas between 5.1 and $10 \%$; 3 , lesion areas between 10.1 and 20\%; 4, lesion areas between 20.1 and 30\%; and 5, between 30.1 and 50\% (Conn et al., 1990). Disease severity was calculated by the following formula: Disease severity $(\%)=[\Sigma($ disease index $\times$ number of infected leaves)/total number of leaves $\times 5] \times$ 100.

Statistical analysis. Each treatment contained at least four replicates and experiments were conducted at least two times. Data were analyzed by ANOVA using SAS/STAT software version 9.0 (SAS Institute Inc., Cary, NC, USA). Significance of treatments was determined using Fisher's least significant difference test $(P \leq 0.05)$.

\section{Results}

Screening antagonistic bacteria from fermented vegetables. In total, $22 \mathrm{LAB}$ strains were recovered from fermented vegetable juices based on the ability to inhibit PccZL3 using filter paper disc overlaid plate assays. The antagonistic activity was examined further on radish root slices (Fig. 1). LAB strains were cultured in MRS, mixed with PccZL3 suspensions, and together placed on a filter 
No chitosan
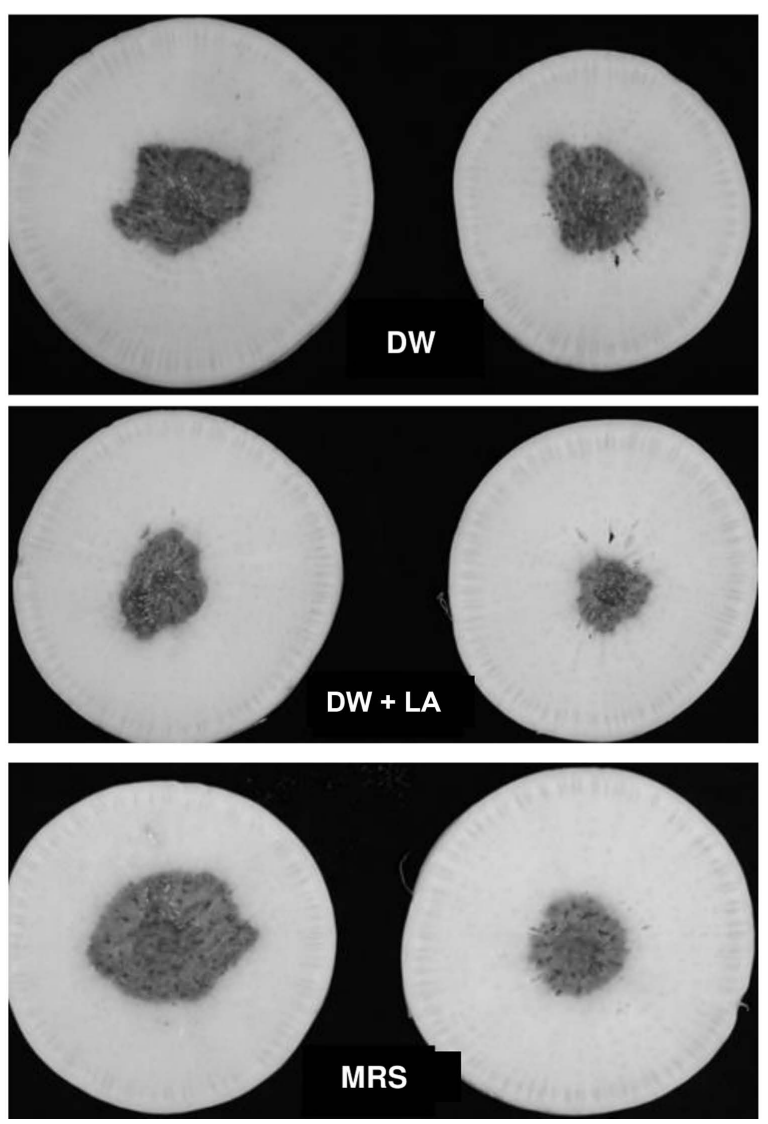

No chitosan
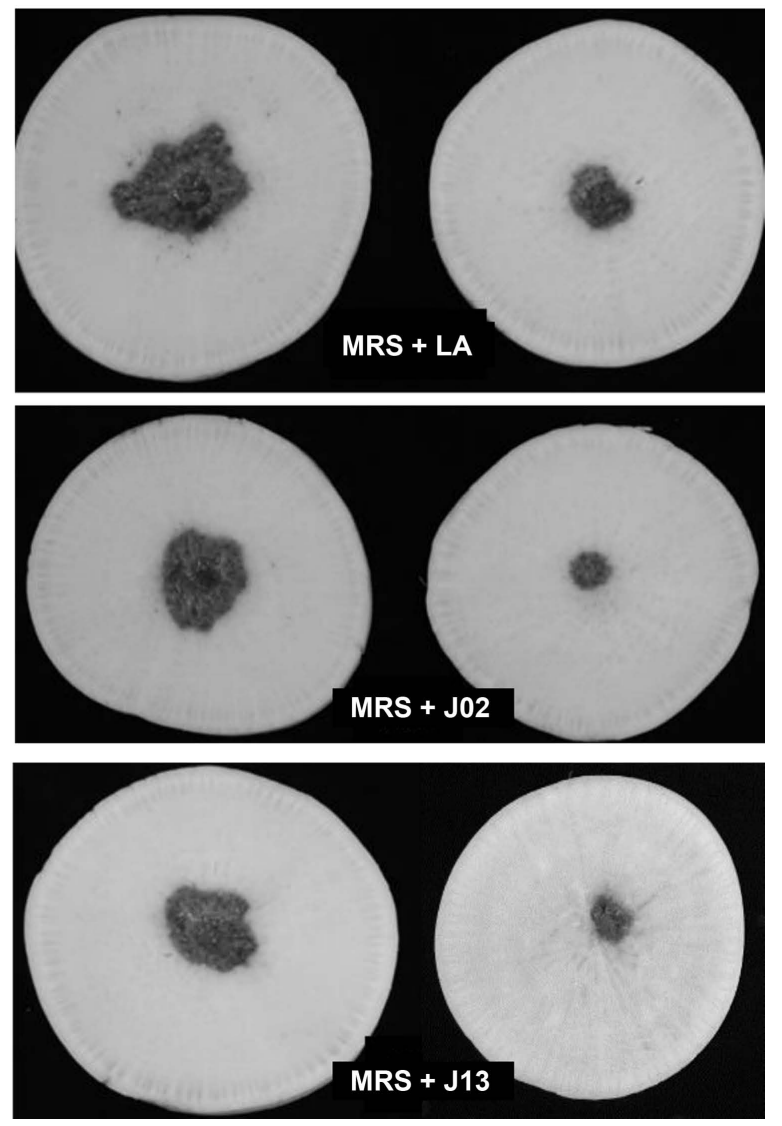

Fig. 1. Chitosan is required for the ability of lactic acid bacteria (LAB) J02 and J13 to reduce soft rot severity on radish slices. A filter paper disc assay for soft rot severity on radish slices. LAB strains were cultured in De Man, Rogosa and Sharpe (MRS) medium for 5 days, diluted $400 \times$, and mixed with $1 \%$ chitosan. Both LAB broth and Pectobacterium carotovorum subsp. carotovorum (Pcc) suspensions $\left(10^{8}\right.$ colony-forming unit $\left./ \mathrm{ml}\right)\left(35 \mu \mathrm{l}\right.$ each) were applied onto a filter paper disc overlaid on radish and incubated at $30^{\circ} \mathrm{C}$ for 2 days. $P c c$ suspensions mixed with distilled water (DW), MRS medium, and DW + or MRS $+2 \%$ lactic acid (LA) were used as mock controls.

paper overlaid on radish. PccZL3 mixed with water and $1 \%$ chitosan induced necrotic lesions on radish. In the presence of chitosan, mixing 2\% lactic acid with PccZL3 significantly inhibited the formation of lesions, while mixing MRS medium with PccZL3 had no effects. Two LAB strains designated $\mathrm{J} 02$ and $\mathrm{J} 13(400 \times$ dilution, $\mathrm{v} / \mathrm{v})$ reduced soft rot severity on radish when mixing with chitosan. In the absence of chitosan, J02 and J13 failed to effectively suppress the development of soft rot lesions (Table 2). Chitosan alone dissolved in $2 \%$ lactic acid also had suppressive effects on soft rot severity, which were significantly less effective than chitosan/LAB.

Identification of LAB. J02 exhibited similarity with Lactobacillus pentosus based on the analyses using a Biolog GEN III MicroStation system and comparison with Biolog's database. J13 showed similarity with Leuconostoc fallax. Further analysis revealed that J02 16S rRNA sequenc- es shared $99 \%$ identity to those of L. pentosus deposited in the database. J13 16s RNA sequences shared 99\% identity to those of $L$. fallax. Phylogenetic analysis suggested that $\mathrm{J} 02$ was closely related to $L$. pentosus and $\mathrm{J} 13$ was closely related to L. fallax (Supplementary Fig. 1).

Assessment of the nitrogen sources to culture LAB for suppression of soft rot. Since chitosan increased the antagonistic ability, $1 \%$ chitosan was added into LAB broth cultures for further tests thereafter. J02 or J13 cultured in MRS and mixed with chitosan suppressed the expansion of soft rot lesions on radish roots (\#2 treatments in Fig. 2A). To improve the antagonistic effects and to identify a cheaper ingredient for future application, eight nitrogen sources were tested. When J02 and J13 were cultured in a modified MRS, in which both peptone and beef extract in MRS were omitted and replaced with other nitrogen source, the lesion suppression activities varied between $\mathrm{J} 02$ and $\mathrm{J} 13$ and 
Table 2. Synergistic effect of chitosan and lactic acid bacteria J02 and J13 on the reduction of soft rot severity as assayed on radish slices

\begin{tabular}{|c|c|c|c|c|}
\hline \multirow{3}{*}{ Treatment $^{\mathrm{a}}$} & \multicolumn{4}{|c|}{ Area of necrotic lesions $\left(\mathrm{mm}^{2}\right)^{b}$} \\
\hline & \multicolumn{2}{|c|}{$200 \times$} & \multicolumn{2}{|c|}{$400 \times$} \\
\hline & Chitosan & Mock & Chitosan & Mock \\
\hline $\mathrm{MRS}+\mathrm{J} 02$ & $0 \mathrm{c} \mathrm{B}$ & $500 \pm 40.83 \mathrm{~b} \mathrm{~A}$ & $37.75 \pm 8.07 \mathrm{~cd} \mathrm{~B}$ & $347.5 \pm 23.72$ bc A \\
\hline $\mathrm{MRS}+\mathrm{J} 13$ & $0 \mathrm{c} \mathrm{B}$ & $803.25 \pm 87.85 \mathrm{a} A$ & $0 \mathrm{~dB}$ & $333 \pm 28.67 \mathrm{c} \mathrm{A}$ \\
\hline $\mathrm{MRS}+\mathrm{LA}$ & $0 \mathrm{c} \mathrm{B}$ & $291 \pm 12.72 \mathrm{~cd} \mathrm{~A}$ & $139.5 \pm 14.34 \mathrm{bc} \mathrm{B}$ & $504.75 \pm 82.67 \mathrm{ab} \mathrm{A}$ \\
\hline MRS & $237 \pm 11.20 \mathrm{~b} \mathrm{~B}$ & $860.5 \pm 89.73 \mathrm{a} \mathrm{A}$ & $217 \pm 21.83 \mathrm{~b} \mathrm{~A}$ & $236.75 \pm 27.60 \mathrm{c} \mathrm{A}$ \\
\hline $\mathrm{DW}+\mathrm{LA}$ & $0 \mathrm{c} \mathrm{B}$ & $112.75 \pm 4.09 \mathrm{~d} \mathrm{~A}$ & $156.25 \pm 25.24 \mathrm{~b} \mathrm{~B}$ & $319.5 \pm 48.87$ c A \\
\hline DW & $411.5 \pm 28.15 \mathrm{a} \mathrm{A}$ & $333.5 \pm 73.73 \mathrm{bc} \mathrm{A}$ & $485.5 \pm 80.17 \mathrm{a} \mathrm{A}$ & $649.25 \pm 92.10 \mathrm{a} \mathrm{A}$ \\
\hline
\end{tabular}

${ }^{a}$ Lactic acid bacteria were cultured in De Man, Rogosa and Sharpe (MRS) at $37^{\circ} \mathrm{C}$ for 5 days, diluted, and mixed with $1 \%$ chitosan. Both lactic acid bacteria broth and P. carotovorum subsp. carotovorum (Pcc) suspensions ( $10^{8}$ colony-forming unit $\left./ \mathrm{ml}\right)(35 \mu 1$ each) were applied onto a filter paper disc overlaid on radish as shown in Fig. 1 and incubated at $30^{\circ} \mathrm{C}$ for 2 days. $P c c$ suspensions mixed with distilled water (DW), MRS medium, and DW + or MRS $+2 \%$ lactic acid (LA) were used as mock controls.

${ }^{b}$ Each treatment contained four replicates. Means followed by the same case letters in each panel were not significantly different according to Fisher's least significant difference test $(P \leq 0.05)$. Different lower-case letters indicate a significant difference among various treatments and different capital letters indicate a significant difference between chitosan and mock.

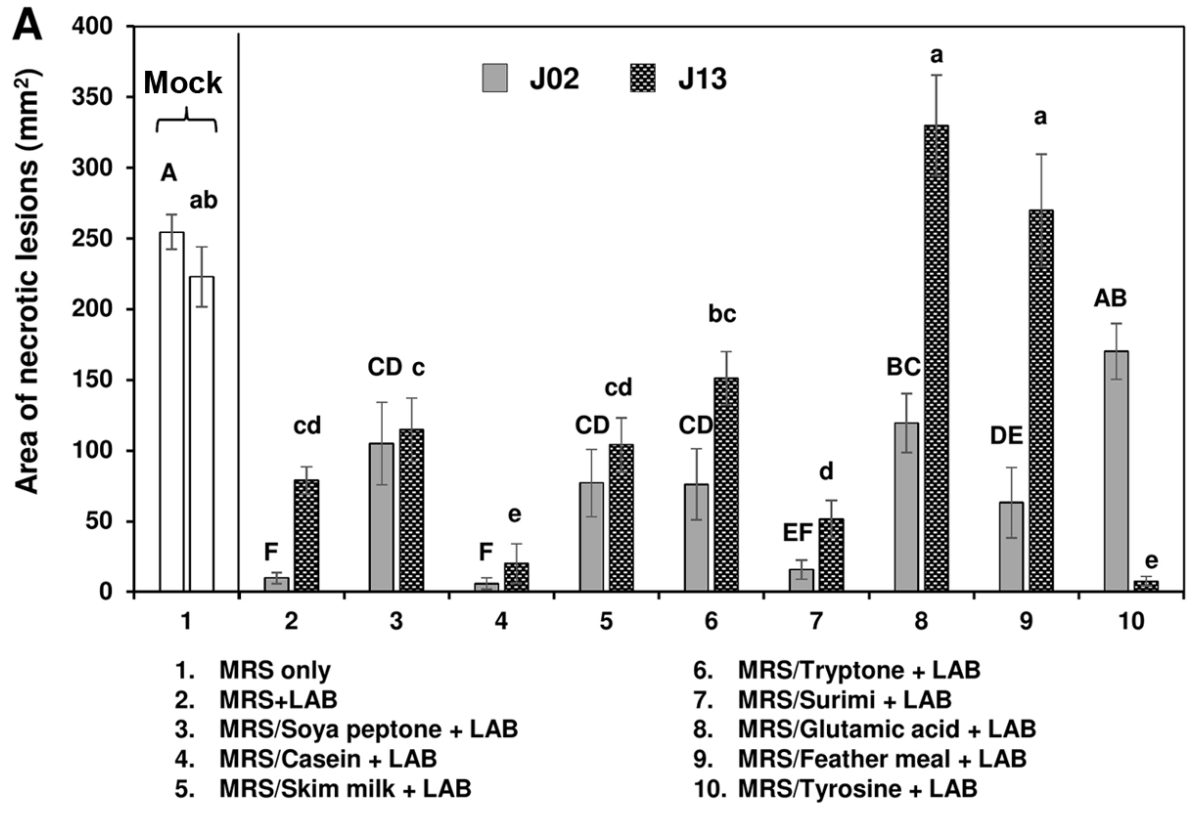

B

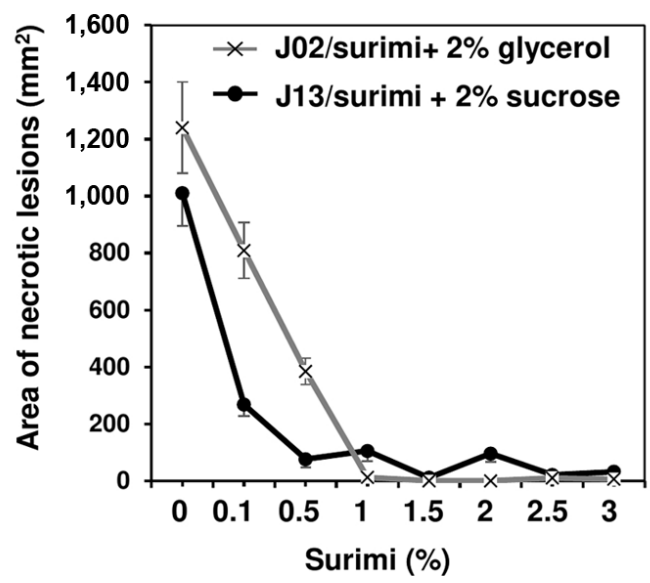

Fig. 2. Effect of nitrogen sources used to culture lactic acid bacteria (LAB) on the reduction of soft rot caused by Pectobacterium carotovorum. (A) The suppressive effectiveness of $\mathrm{J} 02(\mathrm{pH}$ 4.1) and $\mathrm{J} 13$ ( $\mathrm{pH} 5.3$ ) fermented in the modified De Man, Rogosa and Sharpe (MRS) medium containing dextrose as the carbon source and different nitrogen sources on the reduction of soft rot severity on radish. LAB strains were grown in the modified MRS, in which peptone and beef extract were replaced with $2 \%$ each of the nitrogen sources as indicated for 3 days. After adding 1\% chitosan, the resultant solution was tested for the reduction of soft rot on radish using a filter paper disc assay. Means followed by the same case letters in each panel were not significantly different $(P \leq 0.05)$. (B) The effect of surimi in a combination with either glycerol or sucrose on the reduction of soft rot severity on radish. J02 was cultured in the modified MRS containing different concentrations of surimi and $2 \%$ glycerol as the main nitrogen and carbon sources, respectively. J13 was cultured in the modified MRS with different concentrations of surimi and $2 \%$ sucrose. 
among different nitrogen sources. J02 was more effective in the suppression of soft rot than J13. Among eight nitrogen sources tested, J02 cultured in MRS or the modified MRS using casein or surimi as the main nitrogen source $(\mathrm{pH}$ 4.1) resulted in a strong suppression in lesion sizes. The suppressive ability on the lesion expansion was comparable to J02 cultured in MRS containing peptone and beef extract as nitrogen sources. Similar results were observed when using $\mathrm{J} 13$ (pH 5.3) as the test strain. It was noticed that glutamic acid or chicken feather meal when used as the main nitrogen source to culture J13 but not J02 had no effects on disease suppression. Using tyrosine as the nitrogen source to grow $\mathrm{J} 13$ resulted in a strong disease suppression; however, tyrosine had no effects when it was used to grow J02. MRS or modified MRS with different nitrogen or carbon source alone had no suppressive effects (data not shown). For both J02 and J13, the disease suppressive abil- ity increased with the increasing concentration of surimi as the nitrogen source and dextrose as the carbon source to culture LAB (Fig. 2B). Modified MRS with surimi and 2\% glycerol or sucrose alone had no suppressive effects (data not shown).

Assessment of the carbon sources to culture LAB for suppression of soft rot. Eight different carbon sources were used to culture LAB in order to identify the effective yet cheaper carbon source for future application. Using surimi as the nitrogen source and fructose, sucrose, dextrin, or glycerol as the carbon source to culture $\mathrm{J} 02$ ( $\mathrm{pH} 4.1$ ) resulted in a great suppression on soft rot lesions (Fig. 3A). Glycerol combined with surimi to culture J02 resulted in the most effective on disease suppression. Using maltose or corn meal as the carbon source to culture J02 had less or no effect, however. When culturing J13, fructose or sucrose

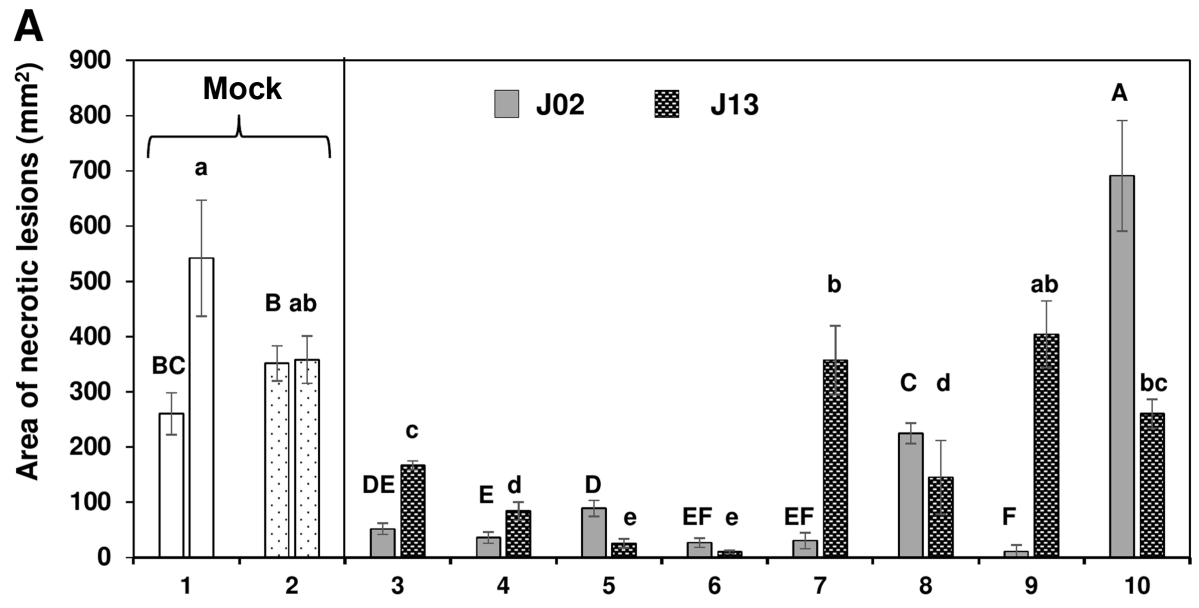

1. MRS only

2. MRSS: Modified MRS using surimi as the nitrogen source

3. MRS +LAB

4. MRSS +LAB

5. MRSS/Fructose $+\mathrm{LAB}$

B

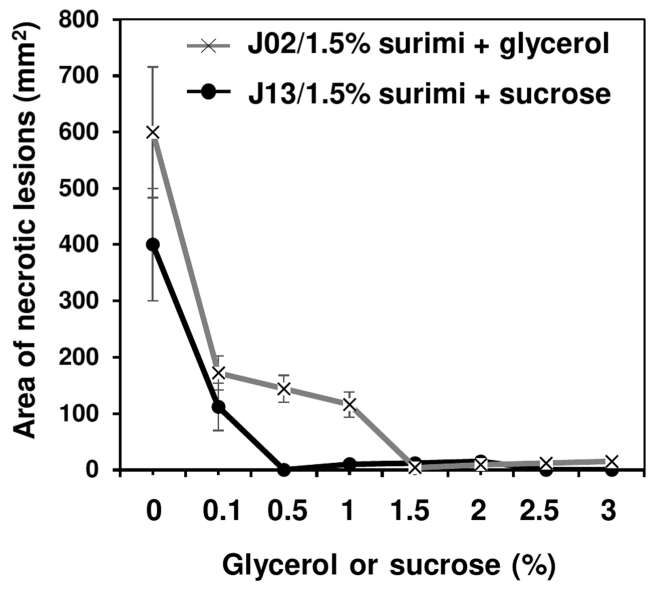

Fig. 3. Effect of carbon sources used to culture lactic acid bacteria (LAB) on the reduction of soft rot caused by Pectobacterium carotovorum. (A) The suppressive effectiveness of LAB strains (J02 and J13) fermented in the modified De Man, Rogosa and Sharpe (MRS) medium containing $1.5 \%$ surimi as the nitrogen source and different carbon sources on the reduction of soft rot severity on radish. LAB strains were grown in the modified MRS, in which dextrose was replaced with $2 \%$ each of the carbon sources as indicated for 3 days. The final pHs of medium after culturing J02 and J13 were estimated to be 4.1 and 5.3, respectively. After adding $1 \%$ chitosan, the resultant solution was tested for the reduction of soft rot on radish using a filter paper disc assay. Means followed by the same case letters in each panel were not significantly different $(P \leq 0.05)$. (B) The effect of glycerol or sucrose in a combination with surimi on the reduction of soft rot severity on radish. J02 was cultured in the modified MRS containing different concentrations of glycerol and $1.5 \%$ surimi as the main carbon and nitrogen sources, respectively. J13 was cultured in different concentrations of sucrose and $1.5 \%$ surimi. 
Table 3. Inhibition of plant pathogens by broth cultures of Lactobacillus pentosus J02 mixing with 1\% chitosan ${ }^{\mathrm{a}}$

\begin{tabular}{|c|c|c|c|c|c|}
\hline \multirow{2}{*}{ Dilution rate } & \multicolumn{5}{|c|}{ Inhibition (\%) } \\
\hline & ABA31 & PA01 & Focn38 & SR & XCC70 \\
\hline $2 \times$ & ND & ND & ND & $100.0 \pm 0.0 \mathrm{~A}$ & $14.4 \pm 0.9$ \\
\hline $10 \times$ & $98.7 \pm 0.4 \mathrm{AB}$ & $98.0 \pm 1.2 \mathrm{~A}$ & ND & $46.7 \pm 3.3 \mathrm{~B}$ & 0 \\
\hline $20 \times$ & $99.0 \pm 0.6 \mathrm{AB}$ & $70.2 \pm 1.4 \mathrm{~B}$ & ND & ND & ND \\
\hline $50 \times$ & $99.7 \pm 0.3 \mathrm{~A}$ & $34.0 \pm 9.7 \mathrm{C}$ & $96.5 \pm 1.2 \mathrm{~A}$ & $16.7 \pm 3.3 \mathrm{C}$ & ND \\
\hline $100 \times$ & $99.0 \pm 0.6 \mathrm{AB}$ & $18.1 \pm 3.0 \mathrm{D}$ & $95.7 \pm 3.1 \mathrm{~A}$ & $13.3 \pm 8.8 \mathrm{C}$ & 0 \\
\hline $200 \times$ & $97.6 \pm 0.4 \mathrm{~B}$ & $5.7 \pm 0.7 \mathrm{DE}$ & $99.3 \pm 0.4 \mathrm{~A}$ & ND & 0 \\
\hline $400 \times$ & $98.3 \pm 0.9 \mathrm{AB}$ & $0.7 \pm 1.8 \mathrm{E}$ & $-3.5 \pm 10.0 \mathrm{~B}$ & ND & 0 \\
\hline
\end{tabular}

ABA31, Alternaria brassicicola; PA01, Colletotrichum higginsianum; Focn38, Fusarium oxysporum f. sp. rapae; SR, Sclerotium rolfsii; XCC, Xanthomonas campestris pv. campestris; ND, not determined.

${ }^{a}$ Each treatment contained four replicates. Means followed by the same case letters in each panel were not significantly different $(P \leq 0.05)$.

combined with surimi (pH 5.3) resulted in a greater suppression on soft rot compared to other test carbon sources. When using dextrin, glycerol, or corn meal as the carbon source, J13 failed to effectively suppress soft rot severity on radish. In contrast, sucrose combined with surimi to culture J13 resulted in the most effective on disease suppres-

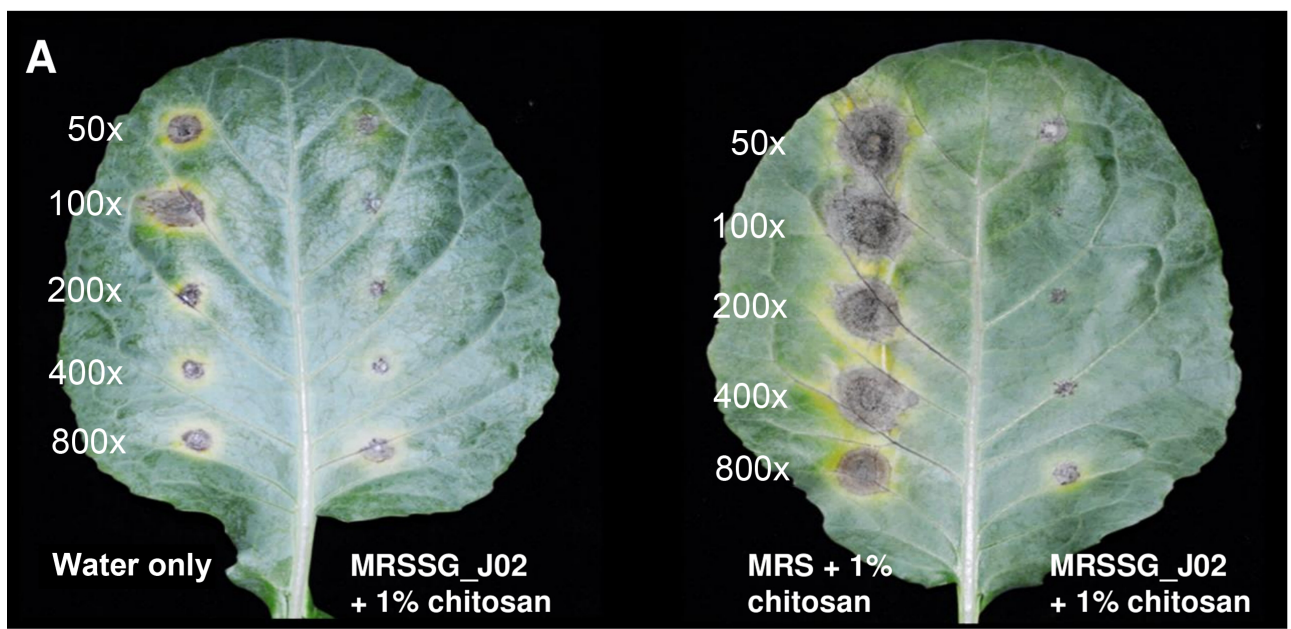

B $\square$ In relation to water control

In relation to MRS + chitosan

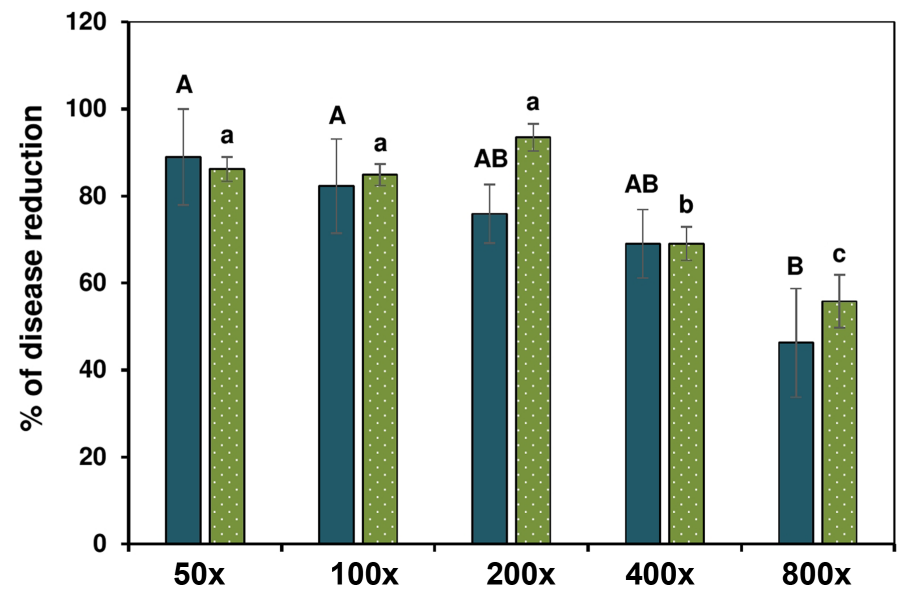

Fig. 4. J02 and chitosan suppress black spot caused by Alternaria brassicicola on detached cabbage leaves. (A) Images of cabbage leaves after being treated with $\mathrm{J} 02$ broth cultures at an appropriate dilution and challenged with $A$. brassicicola. J02 was cultured in MRSSG (a modified De Man, Rogosa and Sharpe [MRS] medium containing surimi and glycerol, $\mathrm{pH} 4.1$ ) for 3 days and broth cultures were used for biocontrol experiments after mixing with $1 \%$ chitosan. In the absence of $\mathrm{J} 02, A$. brassicicola induced larger lesions on spots treated with MRS and chitosan (right panel) compared to those treated with water only (left panel), likely due to the notion that $A$. brassicicola could obtain nutrients from MRS and grow faster. (B) Quantitative analyses of black spot severity reduction after application of J02 and chitosan in relation to water or MRS medium control. Means followed by the same case letters in each panel were not significantly different $(P \leq 0.05)$. 

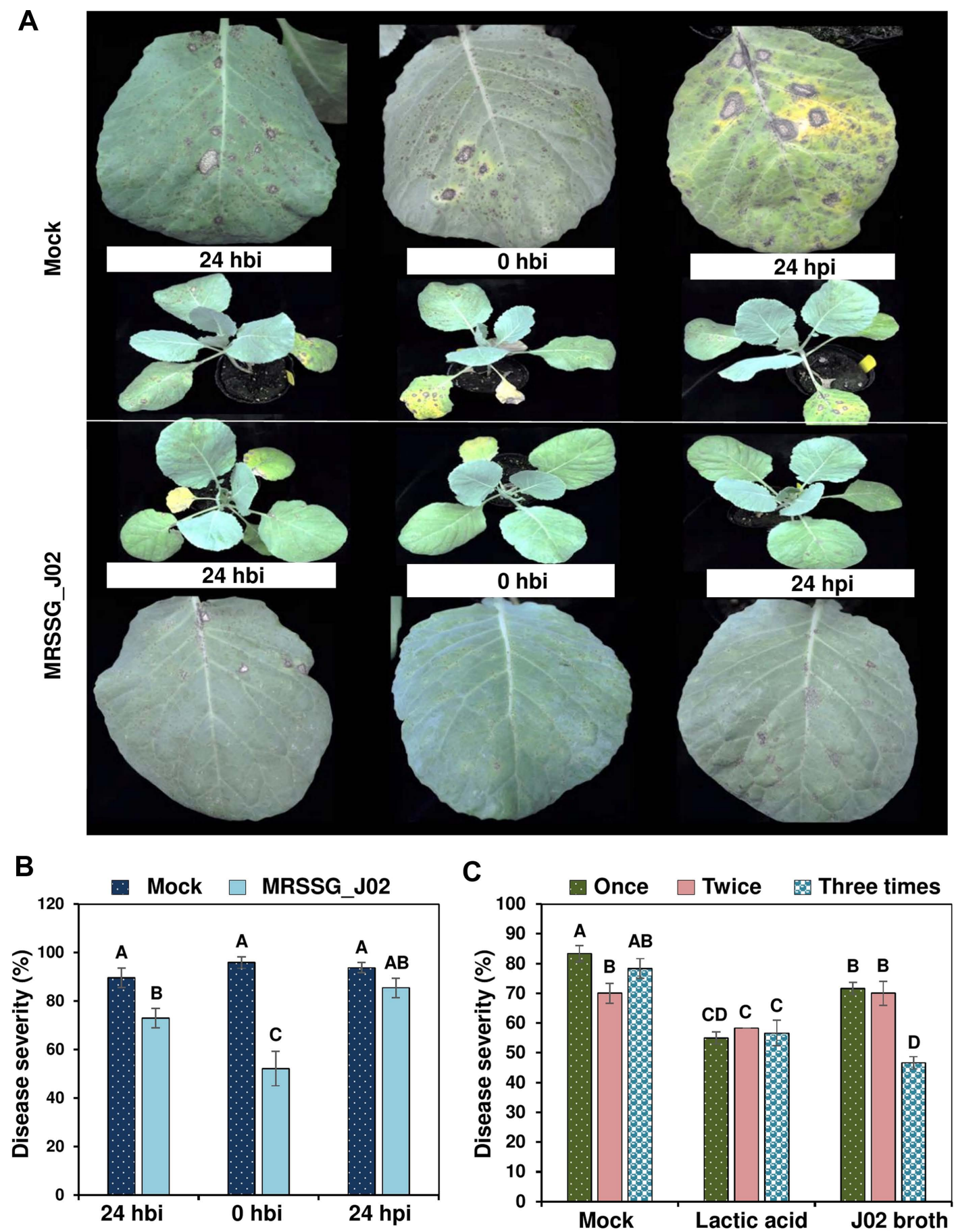

Fig. 5. The timing of application of J02 broth cultures mixing with 1\% chitosan on the reduction of black spot caused by Alternaria brassicicola on the 28-old-day cabbage seedlings. J02 cultured in MRSSG (a modified De Man, Rogosa and Sharpe medium containing surimi and glycerol, $\mathrm{pH} 4$.1) for 3 days was diluted $400 \times$, mixed with $1 \%$ chitosan, and sprayed to cabbage seedlings. (A) Black spot symptoms on cabbage leaves. Seedlings were sprayed with water (control) or $\mathrm{J} 02$ broth and inoculated with spore suspensions $\left(3 \times 10^{4}\right.$ spores $/ \mathrm{ml}$ ) of $A$. brassicicola at $0 \mathrm{~h}, 24 \mathrm{~h}$ before inoculation (hbi), or $24 \mathrm{~h}$ post inoculation (hpi). (B) Reduction of black spot severity on cabbage seedlings after applying J02 broth and chitosan at three different timing. (C) Effect of total applications on the reduction of black spot severity. J02 broth and chitosan were sprayed on to cabbage seedlings at day 28 (one application), days 21 and 28 (two applications), or days 14, 21, and 28 (three applications) and inoculated with spore suspensions of $A$. brassicicola at day 29 . Plants were kept in a greenhouse for 7 days for lesion development. Seedlings sprayed with water (mock) or 2\% lactic acid were used as the controls. Means followed by the same case letters in each panel were not significantly different $(P \leq 0.05)$. 
sion. The disease suppressive ability of J02 increased with the increasing concentration of glycerol surimi as the carbon and nitrogen sources, respectively (Fig. 3B). Similarly, the disease suppressive ability of J13 increased with the increasing concentration of sucrose and surimi as the carbon and nitrogen sources, respectively. Because chitosan could be completely dissolved in $\mathrm{J} 02$ but not in $\mathrm{J} 13$ broth cultures, J02 was used for most of the experiments thereafter.

J02 is effectively antagonistic against fungal pathogens of cruciferous vegetables. To test the ability of LAB to inhibit different plant pathogens of cruciferous vegetables, a MRSSG medium containing $1.5 \%$ surimi and $1.5 \%$ glycerol ( $\mathrm{pH} 4.1)$ as the main nitrogen and carbon sources, respectively, was modified from MRS and used to culture J02. Broth cultures of J02 after being mixed with $1 \%$ chitosan suppressed the germination of spores collected from ABA31 even at a 400-fold dilution (Table 3). J02 broth/ chitosan had less effect on the suppression of spores collected from C. higginsianum. J02 broth/chitosan suppressed the germination of spores from $F$. oxysporum $\mathrm{f}$. sp. rapae Focn38 only at a 200-fold or lower dilution; Focn38 spores even germinated slightly better (negative inhibition values) than mock controls in some tests at a 400-fold dilution. The suppressive activity against $C$. higginsianum was observed when J02 broth/chitosan was applied at a 10 or 20 -fold dilution. J02 broth/chitosan could suppress the germination of sclerotia produced by $S$. rolfsii at a 2-fold dilution and further dilutions of J02 broth had little or no suppressive activity. Similarly, broth cultures of J02 only when applied at a 2-fold dilution had antagonistic activity against $X c c 70$ in the presence of chitosan.

J02 suppresses black spot caused by $A$. brassicicola. J02 was cultured in MRSSG (pH 4.1) for 3 days and broth cultures were used for biocontrol experiments after adding $1 \%$ chitosan. Inoculation assays revealed that $A$. brassicicola induced small lesions on detached cabbage leaves after being treated with $\mathrm{J} 02$ broth cultures and mixing with chitosan (Fig. 4A). In contrast, A. brassicicola induced large necrotic lesions on cabbage treated with water or MRS only. Quantitation of disease severity revealed that J02 broth even at a 400-fold dilution could reduce black spot lesions by more than $70 \%$ compared to those of water or MRS mock controls (Fig. 4B). At a-800-fold dilution, J02 broth reduced cabbage black spot severity by $\sim 50 \%$. Greenhouse trails also revealed that J02 broth at a 200-fold dilution reduced black spot severity on cabbage seedlings considerably (Fig. 5A). Application of J02 broth at a 200fold dilution $24 \mathrm{~h}$ before inoculation or co-application with
A

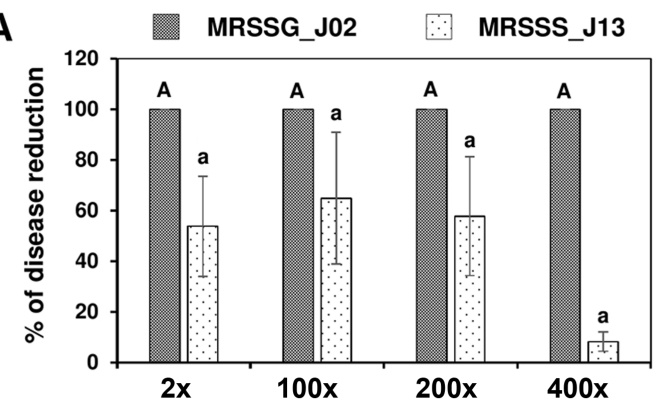

B

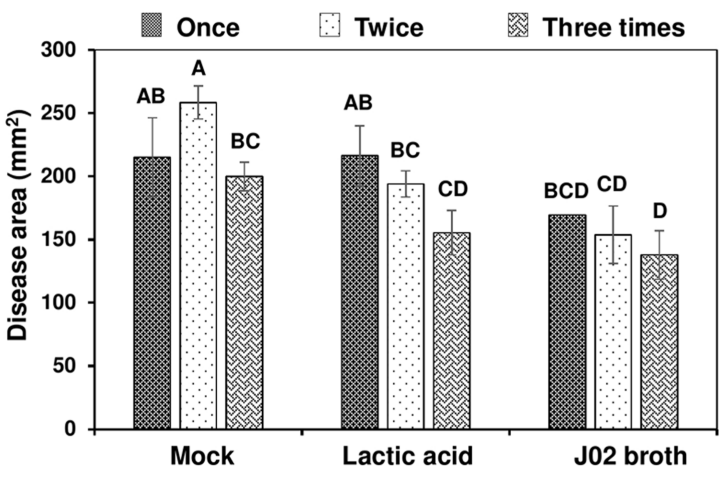

C

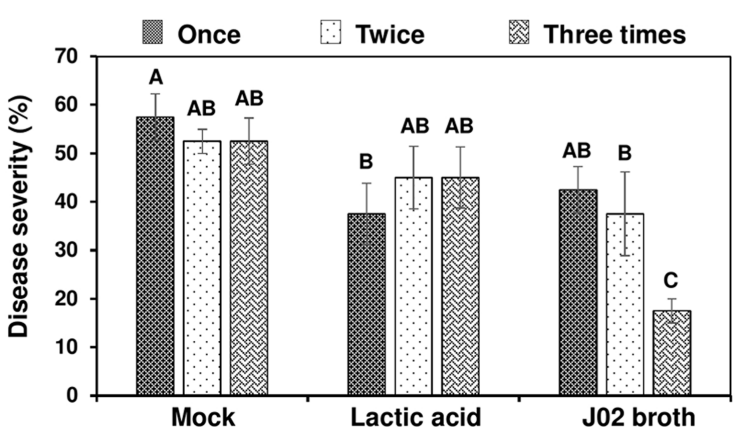

Fig. 6. Reduction of bacterial disease on cabbage leaves after applying J02 or J13 broth mixing with chitosan. (A) Reduction of soft rot on cabbage leaves. J02 and J13 were cultured in MRSSG (a modified De Man, Rogosa and Sharpe medium containing surimi and glycerol, $\mathrm{pH} 4.1$ ) and MRSSS (MRS containing 1.5\% surimi and $0.5 \%$ sucrose, $\mathrm{pH} 5.3$ ), respectively, diluted, and mixed with $1 \%$ chitosan. The resultant solution was mixed with Pectobacterium carotovorum subsp. carotovorum cell suspensions $\left(10^{8}\right.$ colony-forming unit $\left.[\mathrm{cfu}] / \mathrm{ml}\right)$ and applied to longitudinal section of leaf petioles. The treated leaves were maintained in a plastic box for 2 days. (B) Reduction of black rot caused by Xanthomonas campestris pv. campestris (Xcc) on cabbage leaves after being sprayed with $\mathrm{J} 02$ broth cultures plus chitosan and inoculated with Xcc using a scissor-cutting method. (C) Reduction of black rot on cabbage seedlings after being sprayed with J02 broth cultures plus chitosan and inoculated with Xcc using a spraying method. J02 broth and chitosan were sprayed on to cabbage seedlings at day 28 (one application), days 21 and 28 (two applications), or days 14, 21, and 28 (three applications) and inoculated with $X c c$ suspensions $\left(10^{8} \mathrm{cfu} / \mathrm{ml}\right)$ at day 29 . Plants treated with water (mock) or $2 \%$ lactic acid were used as the controls. Means followed by the same case letters in each panel were not significantly different $(P \leq 0.05)$. 
fungal inoculum reduced black spot severity considerably compared to water controls (Fig. 5B). Application of J02 broth and chitosan $24 \mathrm{~h}$ post inoculation was less effective in the reduction of black spot severity on 28-day-old cabbage seedlings. Application of J02 broth at $200 \times$ once (at day 28), twice (at days 21 and 28), or three times (at days 14,21 , and 28) significantly reduced black spot severity (Fig. 5C). Application of $2 \%$ lactic acid also reduced black spot severity on detached leaf assays.

$\mathrm{LAB}$ strains reduce bacterial disease on cabbage leaves. As stated above, broth cultures of LAB reduced soft rot lesions caused by PccZL3 on radish. Inoculation assays on detached cabbage leaf petioles also revealed that application of J02 broth cultures ( $\mathrm{pH} 4.1)$ even at a 400-fold dilution plus $1 \%$ chitosan completely (100\%) suppressed soft rot severity (Fig. 6A). Application of J13 broth plus chitosan was less effective in the reduction of soft rot severity compared to J02. J02 broth cultures and chitosan after being applied onto cabbage leaves three times before inoculation significantly reduced the severity of cabbage black rot caused by $X c c 70$ using either a scissor-cutting inoculation (Fig. 6B) or a spraying inoculation (Fig. 6C) method.

\section{Discussion}

In the present study, we have identified two LAB strains $\mathrm{J} 02$ and J13 from fermented vegetables as Lactobacillus pentosus and Leuconostoc fallax, respectively, based on Biologs and 16S rDNA sequence identity comparisons and have demonstrated their ability to suppress several plant pathogenic fungi and bacteria after adding $1 \%$ chitosan. In the absence of chitosan, the newly identified LAB strains have little or no effect on the reduction of soft rot severity caused by Pcc ZL3. However, the addition of chitosan into LAB broth cultures significantly increases the antagonistic efficacy. Experimental trials have also been performed to demonstrate their potential use as a biocontrol agent for controlling cruciferous vegetable diseases, including soft rot caused by $P c c$, cabbage black spot caused by $A$. brassicicola, and black rot caused by Xcc. Moreover, in-vitro assays reveal that LAB broth cultures after being mixed with chitosan are antagonistic to $C$. higginsianum, $F$. oxysporum f. sp. rapae, and $S$. rolfsii, indicating broad biological activity of a combination of LAB and chitosan.

LAB strains capable of forming inhibitory zones on plate assays may not be able to exhibit disease reduction in-plan$t a$. This indicates that the ability to suppress plant diseases shall be experimentally tested for any given LAB strain. Of 22 LAB strains tested, two strains J02 and J13 are able to suppress soft rot disease on radish roots only in the presence of chitosan. In the absence of chitosan, J02 and J13 fail to suppress soft rot. Chitosan alone is moderately effective on the suppression of soft rot severity; however, a combination of chitosan and a LAB strain displays much greater disease suppression, indicating a synergistic effect between chitosan and the LAB strain.

The mechanisms by which LAB strains contribute to antimicrobial ability are multifaceted (Castellano et al., 2017). LAB could produce lactic acid and acetic acid that will lower $\mathrm{pH}$ and inhibit microbial growth (Cabo et al., 2002). In addition to lower $\mathrm{pH}$, acids produced by $\mathrm{LAB}$ strains can disrupt bacterial membrane and inhibit enzymatic activities (Alakomi et al., 2000). LAB strains are also known to produce a diverse of metabolites, including $\mathrm{H}_{2} \mathrm{O}_{2}$, diacetyl, phenolics, bacteriocins, and other proteinaceous compounds (Arena et al., 2016; Gajbhiye and Kapadnis, 2016), which may play an important role in disease suppression. Some LAB strains can produce siderophores, indole acetic acid, and phosphate (Shrestha et al., 2014). The metabolic products of $\mathrm{J} 02$ and $\mathrm{J} 13$ strains in the presence and absence of chitosan warrant further research.

Chitosan is often dissolved in aqueous acid solution (Bégin and Van Calsteren, 1999) and is used to reduce various plant diseases (El Hadrami et al., 2010; Hassan and Chang, 2017). Chitosan is a critical element in the antagonistic activity of J02 and J13. Neither chitosan nor LAB alone can effectively suppress soft rot disease on radish. By contrast, a combination of chitosan and J02 or J13 significantly increases the ability to suppress soft rot disease, indicating a synergistic effect between chitosan and LAB strains. However, the interaction is apparently influenced by nutritional factors. In the presence of chitosan, the type of carbon and nitrogen sources used to culture a LAB strain has a profound impact on the suppression of soft rot disease. This may be due to different secondary metabolites produced by $\mathrm{LAB}$ under different nutritional conditions. The production of secondary metabolites by J02 or J13 could very likely play an important role in antagonistic activity as suggested in other LAB strains (Gajbhiye and Kapadnis, 2016). Chitosan itself could damage cell membrane, increase permeability, and change cell structure, and thus is toxic to plant pathogens (Lopez-Moya et al., 2019; Rabea et al., 2003; Xing et al., 2015). Chitosan can promote plant growth (Rabea et al., 2003) and induce plant defense reactions (Konappa et al., 2016; Malerba and Cerana, 2016). Moreover, chitosan could be degraded by LAB to form different metabolic products, which could exhibit a stronger toxicity against plant pathogens. Some bacteria have been reported to degrade chitosan (Sawaguchi et al., 2015). Whether or 
not J02 or J13 can degrade chitosan remains unknown.

MRS medium contains peptone, beef extract, and dextrose as the major nutritional sources. To identify cheaper and equally effective materials to culture LAB, a diverse of compounds and materials including two agricultural wastes, surimi and chicken feather meal, were tested. Using feather meal as the major nitrogen source to culture $\mathrm{J} 02$ or J13 results in a moderate or no effect on the disease suppression. In contrast, using surimi as the major nitrogen source to culture the LAB strains results in a drastic reduction of soft rot disease severity. Taiwan is an island country producing enormous fish surimi for foods as well as agricultural feeds. Thus, using surimi to culture LAB could reduce production costs considerably. In addition to surimi, fructose and sucrose can be used to replace dextrose to culture LAB and achieve similar efficacy on disease suppression. Using glycerol or dextrin as the main carbon source to culture $\mathrm{J} 02$ but not $\mathrm{J} 13$ results in a considerable reduction in soft rot severity. Glycerol has been reported to increase the toxic effects of a LAB strain against pathogens (Toplaghaltsyan et al., 2017). The results indicate that the medium composition used to culture a LAB strain could affect the efficacy of anti-microbial activity and disease reduction, and the fermentation conditions shall be experimentally optimized for a given biocontrol agent.

J02 after being cultured in a modified MRS using surimi as the nitrogen source and glycerol as the carbon source, together with chitosan has a strong antagonistic activity against $A$. brassicicola, $C$. higginsianum, $F$. oxysporum $\mathrm{f}$. sp. rapae, and PccZL3. Broth cultures of J02 plus chitosan are less toxic to $S$. rolfsii and Xcc70. J02 broth cultures effectively reduce cabbage black spot severity caused by A. brassicicola either on detached leaves or in the whole plant assay. Delayed application of culture filtrates is less effective. We also have found that multiple applications of J02 broth cultures result in better efficacy on the reduction of cabbage black spot than a single application. J02 broth cultures can reduce soft rot disease on both radish roots and cabbage leaves. Although J02 broth cultures are less toxic to $X c c 70$, greenhouse trials have revealed that $\mathrm{J} 02$ broth cultures mixing with chitosan can significantly reduce black rot severity caused by $X c c 70$ on cabbage leaves, particularly after multiple applications using spraying. Disease reduction after application of J02 broth cultures plus chitosan could be attributable to the direct toxicity of chitosan and/or secondary metabolites produced by J02, as well as defense reactions triggered by $\mathrm{LAB}$, chitosan and other unknown components in the broth cultures. Some LAB strains have been evaluated to activate plant defense mechanisms (Konappa et al., 2016). In addition, LAB strains may show competition for space and nutrients with plant pathogens (Tsuda et al., 2016). In conclusion, the present study has offered an opportunity for future research on how to formulate and maximize the effectiveness of a $\mathrm{LAB}$ strain for disease management, which may lead to achieve sustainable agriculture.

\section{Acknowledgments}

This research was supported by the "Innovation and Development Center of Sustainable Agriculture" under the Higher Education Sprout Project from the Ministry of Education, Taiwan, R.O.C. to JWH.

\section{Electronic Supplementary Material}

Supplementary materials are available at The Plant Pathology Journal website (http://www.ppjonline.org/).

\section{References}

Abd-El-Kareem, F., El-Mougy, N. S., El-Gamal, N. G. and Fotouh, Y. O. 2006. Use of chitin and chitosan against tomato root rot disease under greenhouse conditions. Res. J. Agric. Biol. Sci. 2:147-152.

Alakomi, H.-L., Skyttä, E., Saarela, M., Mattila-Sandholm, T., Latva-Kala, K. and Helander, I. M. 2000. Lactic acid permeabilizes gram-negative bacteria by disrupting the outer membrane. Appl. Environ. Microbiol. 66:2001-2005.

Arena, M. P., Silvain, A., Normanno, G., Grieco, F., Drider, D., Spano, G. and Fiocco, D. 2016. Use of Lactobacillus plantarum strains as a bio-control strategy against food-borne pathogenic microorganisms. Front. Microbiol. 7:464.

Axel, C., Brosnan, B., Zannini, E., Furey, A., Coffey, A. and Arendt, E. K. 2016. Antifungal sourdough lactic acid bacteria as biopreservation tool in quinoa and rice bread. Int. J. Food Microbiol. 239:86-94.

Bégin, A. and Van Calsteren, M. R. 1999. Antimicrobial films produced by chitosan. Int. J. Macromol. 26:63-67.

Cabo, M. L., Braber, A. F. and Koenraad, P. M. F. J. 2002. Apparent antifungal activity of several lactic acid bacteria against Penicillium discolor is due to acetic acid in the medium. $J$. Food Prot. 65:1309-1316.

Castellano, P., Pérez Ibarreche, M., Blanco Massani, M., Fontana, C. and Vignolo, G. M. 2017. Strategies for pathogen biocontrol using lactic acid bacteria and their metabolites: a focus on meat ecosystems and industrial environments. Microorganisms 5:E38.

Chirkov, S. N. 2002. The antiviral activity of chitosan (review). Appl. Biochem. Microbiol. 38:1-8.

Colombo, M., Castilho, N. P. A., Todorov, S. D. and Nero, L. A. 2018. Beneficial properties of lactic acid bacteria naturally present in dairy production. BMC Microbiol. 18:219. 
Conn, K. L., Tewari, J. P. and Awasthi, R. P. 1990. A disease assessment key for Alternaria blackspot in rapeseed and mustard. Can. Plant Dis. Surv. 70:19-22.

Crowley, S., Mahony, J. and van Sinderen, D. 2013. Current perspectives on antifungal lactic acid bacteria as natural biopreservatives. Trends Food Sci. Technol. 33:93-109.

Daranas, N., Roselló, G., Cabrefiga, J., Donati, I., Francés, J., Badosa, E., Spinelli, F., Montesinos, E. and Bonaterra, A. 2019. Biological control of bacterial plant diseases with Lactobacillus plantarum strains selected for their broad-spectrum activity. Ann. Appl. Biol. 174:92-105.

De Man, J. C., Rogosa, M. and Sharpe, M. E. 1960. A medium for the cultivation of Lactobacilli. J. Appl. Bacteriol. 23:130135.

El Hadrami, A., Adam, L. R., El Hadrami, I. and Daayf, F. 2010. Chitosan in plant protection. Mar. Drugs 8:968-987.

Gajbhiye, M. H. and Kapadnis, B. P. 2016. Antifungal-activityproducing lactic acid bacteria as biocontrol agents in plants. Biocontrol Sci. Technol. 26:1451-1470.

Hadwiger, L. A. 2013. Multiple effects of chitosan on plant systems: solid science or hype. Plant Sci. 208:42-49.

Hassan, N., Nakasuji, S., Elsharkawy, M. M., Naznin, H. A., Kubota, M., Ketta, H. and Shimizu, M. 2017. Biocontrol potential of an endophytic Streptomyces sp. strain MBCN1521 against Alternaria brassicicola on cabbage plug seedlings. Microbes Environ. 32:133-141.

Hassan, O. and Chang, T. 2017. Chitosan for eco-friendly control of plant disease. Asian J. Plant Pathol. 11:53-70.

Huang, J.-S., Peng, Y. H., Chung, K.-R. and Huang, J.-W. 2018. Suppressive efficacy of volatile organic compounds produced by Bacillus mycoides on damping-off pathogens of cabbage seedlings. J. Agric. Sci. 156:795-809.

Konappa, N. M., Malini, M., Uzma, F., Krishnamurthy, S., Nayaka, S. C., Niranjana, S. R. and Chowdappa, S. 2016. Lactic acid bacteria mediated induction of defense enzymes to enhance the resistance in tomato against Ralstonia solanacearum causing bacterial wilt. Sci. Hortic. 207:183-192.

Laitila, A., Alakomi, H.-L., Raaska, L., Mattila-Sandholm, T. and Haikara, A. 2002. Antifungal activities of two Lactobacillus plantarum strains against Fusarium moulds in vitro and in malting of barley. J. Appl. Microbiol. 93:566-576.

Lin, W., Hu, X., Zhang, W., Rogers, W. J. and Cai, W. 2005. Hydrogen peroxide mediates defence responses induced by chitosans of different molecular weights in rice. J. Plant Physiol. 162:937-944.

Litterick, A. M., Harrier, L., Wallace, P., Watson, C. A. and Wood, M. 2004. The role of uncomposted materials, composts, ma- nures, and compost extracts in reducing pest and disease incidence and severity in sustainable temperate agricultural and horticultural crop production: a review. Crit. Rev. Plant Sci. 23:453-479.

Lopez-Moya, F., Suarez-Fernandez, M. and Lopez-Llorca, L. V. 2019. Molecular mechanisms of chitosan interactions with fungi and plants. Int. J. Mol. Sci. 20:332.

Malerba, M. and Cerana, R. 2016. Chitosan effects on plant systems. Int. J. Mol. Sci. 17:996.

Mokoena, M. P. 2017. Lactic acid bacteria and their bacteriocins: classification, biosynthesis and applications against uropathogens: a mini-review. Molecules 22:1255.

Morin-Crini, N., Lichtfouse, E., Torri, G. and Crini, G. 2019. Applications of chitosan in food, pharmaceuticals, medicine, cosmetics, agriculture, textiles, pulp and paper, biotechnology, and environmental chemistry. Environ. Chem. Lett. 17:1667-1692.

Rabea, E. I., Badawy, M. E.-T., Stevens, C. V., Smagghe, G. and Steurbaut, W. 2003. Chitosan as antimicrobial agent: applications and mode of action. Biomacromolecules 4:1457-1465.

Sawaguchi, A., Ono, S., Oomura, M., Inami, K., Kumeta, Y., Honda, K., Sameshima-Saito, R., Sakamoto, K., Ando, A. and Saito, A. 2015. Chitosan degradation and associated changes in bacterial community structures in two contrasting soils. Soil Sci. Plant Nutr. 61:471-480.

Shrestha, A., Kim, B. S. and Park, D. H. 2014. Biological control of bacterial spot disease and plant growth-promoting effects of lactic acid bacteria on pepper. Biocon. Sci. Technol. 24:763-779.

Toplaghaltsyan, A., Bazukyan, I. and Trchounian, A. 2017. The effects of different carbon sources on the antifungal activity by lactic acid bacteria. Curr. Microbiol. 74:168-174.

Tsuda, K., Tsuji, G., Higashiyama, M., Ogiyama, H., Umemura, K., Mitomi, M., Kubo,Y. and Kosaka, Y. 2016. Biological control of bacterial soft rot in Chinese cabbage by Lactobacillus plantarum strain BY under field conditions. Biol. Control 100:63-69.

Verlee, A., Mincke, S. and Stevens, C. V. 2017. Recent developments in antibacterial and antifungal chitosan and its derivatives. Carbohydr. Polym. 164:268-283.

Weisburg, W. G., Barns, S. M., Pelletier, D. A. and Lane, D. J. 1991. 16S ribosomal DNA amplification for phylogenetic study. J. Bacteriol. 173:697-703.

Xing, K., Zhu, X., Peng, X. and Qin, S. 2015. Chitosan antimicrobial and eliciting properties for pest control in agriculture: a review. Agron. Sustain. Dev. 35:569-588. 